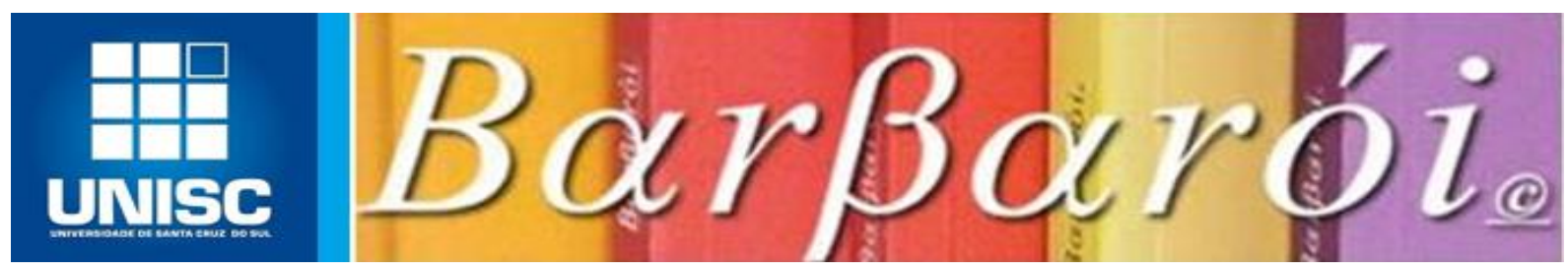

\title{
PERCEPÇÃO MATERNA SOBRE A PARTICIPAÇÃO DO PAI NA HOSPTALIZAÇÃO DO FILHO EM INVESTIGAÇÃO DIAGNÓSTICA DE DOENÇA CRÔNICA
}

\author{
DOI: http://dx.doi.org/10.17058/barbaroi.v0i49.9014 \\ $*$ \\ Taline Cheron \\ Hospital de Clínicas de Porto Alegre - HCPA - Brasil \\ Cláudia Simone Silveira dos Santos \\ Hospital de Clínicas de Porto Alegre - HCPA - Brasil

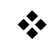

\section{Resumo:}

O estudo objetivou investigar a participação do pai na hospitalização do filho durante a investigação diagnóstica, a partir de relatos da percepção materna. Participaram da pesquisa seis mães, cujos filhos estavam hospitalizados em investigação diagnóstica de doença crônica em um hospital terciário localizado no Sul do pais. Utilizou-se o método qualitativo de caráter exploratório, em que foi realizada entrevista estruturada com as participantes. A análise de conteúdo indicou que a presença do pai na hospitalização gera benefícios tanto para o filho doente, quanto para a mãe/esposa que se sente acolhida, funcionando como principal rede apoio e suporte para organização psíquica da mulher. Destacou-se o intenso sofrimento paterno vivenciado neste momento, a insegurança para realizar alguns cuidados de saúde com o filho e o medo de perdê-lo. As mães percebem os pais envolvidos com seus filhos e com capacidade de desenvolver um vínculo pai/filho positivo em Unidade Pediátrica.

Palavras-chave: Parentalidade; Hospitalização infantil; Vínculo pai/filho.

\section{Introdução:}

A hospitalização de uma criança mobiliza emocionalmente os pais que estão vivenciando este processo, o que faz surgir sentimentos de insegurança e medo que podem alterar a dinâmica familiar. A família se depara com diversas dificuldades no seu funcionamento e rotina devido às mudanças que essa nova situação impõe, gerando fragilidade e vulnerabilidade. Nas práticas hospitalares tem se observado a mãe, como principal cuidadora, acompanhando a internação do seu filho e experiência todas as angústias e dificuldades que este processo gera.

As condições crônicas são definidas como um grupo de problemas de saúde que persistem por longos períodos de tempo e requerem gerenciamento e cuidados permanentes, podendo ou não ser superados. Diferentemente de um quadro agudo, a doença crônica exige uma contínua adaptação e provoca alteração mais ou menos permanente tanto nos papéis 
como na dinâmica familiar, que passa a ser pontuada por uma série de crises que incidem sobre todos os seus membros, com tendência a se agravar ao longo do tempo (OLIVEIRA e SOMMERMAM, 2008).

No contexto de adoecimento infantil, o papel da família na manutenção do bem-estar psicológico, do desenvolvimento emocional e do tratamento é de suma importância. Assim, ser pai e ser mãe de uma criança doente envolve inúmeras demandas, além daquelas normalmente presentes no exercício da parentalidade.

A experiência e atuação como psicóloga em um Programa de Residência Multiprofissional Integrada em Saúde com ênfase na Saúde da Criança, de um hospital de caráter terciário localizado no Sul do país, possibilitou um contato diário com as mães que acompanhavam seus filhos na Internação Pediátrica. Partiu disso a necessidade e o desejo de investigar como ela percebe a participação do pai de seu filho no processo de investigação diagnóstica para doença crônica. A presença da mãe é constante no ambiente hospitalar, porém poucos estudos abordam como esta mulher percebe a participação paterna neste momento de crise familiar - a internação e investigação diagnóstica de doença crônica do filho.

O adoecimento infantil insere a criança no ambiente hospitalar e faz com que necessite de atenção e dedicação dos seus responsáveis. Enfrentar e acompanhar o tratamento demanda intenso envolvimento emocional por parte de seus familiares. Constata-se que a mãe geralmente é a principal cuidadora e passa grande parte da hospitalização envolvida com o cuidado do seu filho(a). Entretanto, nota-se que o pai está tornando-se mais presente e participativo nesse cenário.

Assim, observamos que a intervenção do psicólogo auxilia a equipe no entendimento da dinâmica familiar. Desta forma, os profissionais da saúde podem discutir de maneira mais apropriada o manejo e as condutas necessárias diante de casos de adoecimento crônico, bem como permitindo um espaço de maior participação dos pais, conforme as demandas maternas ao longo da hospitalização do filho. Tendo em vista os aspectos acima mencionados, este artigo se propôs, a partir de relatos da percepção materna, a identificar a participação do pai durante a hospitalização do filho durante a investigação diagnóstica.

\section{1 - Doença crônica infantil e Hospitalização:}

Os efeitos da doença estão interligados aos efeitos da hospitalização, pois assim que a criança adoece e vai para o hospital em busca de ajuda, a família se mostra temerosa e reage de maneira ambígua. Deseja saber o que o filho tem, pois alega que conhecendo a doença 
poderá fornecer-lhe assistência mais adequada; mas por outro lado, nega a doença em si mesma e a necessidade de internação, por ter dificuldade de enfrentar a realidade que se antevê. Observa-se que o mecanismo de negação é utilizado, quer a doença seja grave ou não (DAMASIO; RUMEN, 2005).

A hospitalização do filho, por si só, é um evento atribulador, gerador de estresse e insegurança devido à condição de vulnerabilidade da saúde da criança. $\mathrm{O}$ enfrentamento dessa situação é mais difícil quando a internação é necessária logo após o nascimento, substituindo a idealização da chegada de um bebê saudável pelo enfrentamento das adversidades e dos sentimentos provocados pela hospitalização (SCHMIDT et al, 2012).

A doença crônica é definida como uma condição que afeta as funções do indivíduo em suas atividades diárias por mais de três meses, causa hospitalização durante um mês por ano ou requer o uso de dispositivos especiais de adaptação. Assim, a criança tem a vida irreversivelmente alterada pelos tratamentos e consequências impostos pela doença, tornandose uma experiência multidimensional tanto para ela como para sua família (MUSCARI, 1998).

O cenário em que a doença crônica infantil está inserida remete a experiências desagradáveis para a criança e para seus pais. Envolve vivências estressoras, tais como o recebimento de diagnóstico, os procedimentos invasivos, a incapacidade de realizar tarefas rotineiras, o afastamento das pessoas de sua convivência e muitas vezes da escola, mudanças gerais nas rotinas de vida. Neste contexto três subsistemas estariam interagindo: o paciente e sua enfermidade, a família e sua rede social e os serviços de saúde. A intervenção psicológica deveria orientar-se para o que ocorre em cada um e entre esses subsistemas (GÓNGORA, 1998).

As equipes de saúde, principalmente as equipes de enfermagem têm papel essencial no processo de hospitalização, contribuindo para o apoio e aproximação pais/bebê, na promoção do vínculo entre pais/filhos de tal modo que o estímulo ao toque se traduza em exercício importante para o início da formação do apego. Estas equipes proporcionam um espaço para que os pais sejam devidamente estimulados e orientados a participarem na recuperação e no desenvolvimento do filho, já que em alguns casos, estes se sentem impotentes diante da hospitalização e do distanciamento dele. Diante da impotência gerada pela hospitalização e doença crônica, o envolvimento gradativo e planejado dos pais no processo de cuidado pode representar uma etapa fundamental para a conquista da autonomia, criando nestes um sentimento crescente de competência para a reconquista da paternidade e para a apropriação do filho (SCHMIDT et al, 2012). 
Além das questões de estrutura e dinâmica familiar, as características e fases da doença também interferem na vivência destas crianças e de suas famílias, devendo ser sempre levadas em consideração. Existem três fases na história de doenças crônicas: 1) crise, caracterizada pelo período sintomático que se estende até o início do tratamento; 2) crônica, marcada pela constância, progressão e remissão do quadro de sinais e sintomas; e 3) terminal, que envolve, desde o momento em que a morte passa a ser uma possibilidade, até a sua ocorrência de fato (RIBEIRO, 2004).

Todas as fases de uma doença crônica são marcantes para os pais, já que a doença ocasiona a desestruturação não somente na vida da criança, mas também na vida familiar e conjugal. Na fase crônica, os pais procuram desenvolver certa autonomia, buscando a reestruturação de suas vidas, adaptando rotinas às necessidades impostas pela condição da criança. Configura-se, deste modo, uma nova situação, com o estabelecimento de estratégias para o enfrentamento da complexidade e gravidade da doença (RIBEIRO, 2004).

Através de estudos sobre hospitalização infantil, evidencia-se que, em casos de hospitalização de crianças com idades inferiores à três anos, a permanência das mães durante a internação faz-se essencial a fim de diminuir o impacto emocional causado pela hospitalização. Atualmente as unidades pediátricas permitem e incentivam que os pais permaneçam ao lado de seu filho como estratégia das equipes de saúde dentro das instituições hospitalares para melhor manutenção da saúde mental destas crianças (CASTRO; THOMAS, 2012).

\section{2 - Parentalidade e Paternidade:}

Uma das etapas do ciclo vital, mais importantes dos indivíduos é marcada pela parentalidade, tornar-se mãe ou pai, ocasiona profundas mudanças na personalidade dos mesmos. Com a gestação o homem e a mulher deixam a condição de filhos e surge o esforço psicológico em renunciar este papel, ao mesmo tempo identificam-se com seus próprios pais como referência para exercerem as suas novas funções, agora marcadas pelo exercício da parentalidade (EIZIRIK, 2001).

Parentalidade é um termo que começou a ser utilizado na literatura psicanalítica francesa a partir dos anos 60 com o objetivo de marcar a dimensão de processo e de construção do exercício da paternidade e maternidade. É o estudo dos vínculos de parentesco e processos psicológicos que nas relações familiares se desenvolvem, sendo necessária uma preparação e uma aprendizagem, que diferenciem as gerações. Esse modelo traz a assimetria das relações pais-filhos, que, quando interiorizadas, são quadro de referência organizador das 
representações do mundo e das relações. Então, a parentalidade organiza o pensamento dos pais diante de si mesmos e de seu filho. Ela organiza, igualmente, o pensamento da criança, que aprende as diferentes atribuições de pais e de filhos (ZORNING, 2009; SILVA; PONTON, 2004).

Houzel (2004) traz que o termo parentalidade, surge no sentido de que é preciso "tornar-se pais", ou seja, não basta ser genitor, tanto o pai quanto a mãe devem internalizar, tanto em nível consciente quanto inconsciente, seu funcionamento mental.

Conforme Piccinini (2004), a experiência masculina frente à paternidade é diferente da feminina. A mulher poderá sentir o filho crescer, mexer-se dentro de si, experimentar as mudanças corporais e do desenvolvimento do bebê no seu próprio corpo, dar à luz e amamentá-lo, diante dessas intensas transformações femininas, o homem pode sentir-se excluído deste processo e ainda desencadear sentimentos de ciúme, inveja, ansiedade e solidão.

A gestação em alguns núcleos familiares ainda é vivida como exclusividade das mulheres, onde os homens são vistos apenas como continente de suas ansiedades e eles são excluídos da experiência. Considerando a representação dos papéis masculinos e femininos em nossa cultura, apesar das recentes transformações, é bastante prevalente a manutenção dos estereótipos de gênero que reforçam a dicotomia entre os papéis (FLECK, FALCKE, HACKNER 2005; STAUDT, 2008).

Até poucas décadas atrás, o homem mostrava dificuldade em separar suas atividades sociais e profissionais daquelas de pai, a sua individualidade mantinha-se nas relações com sua família, deixando de lado decisões domésticas, mantendo-se afastado afetivamente dela, cabendo à mulher estas questões. Atualmente há uma nova configuração, desencadeada, principalmente pelos avanços da mulher no mercado de trabalho. Cada vez mais a hierarquia doméstica está se alterando, o homem está assumindo mais tarefas no lar e sua autoridade de patriarca é questionada constantemente, porém ainda há uma grande desigualdade nas responsabilidades (FREITAS, et al 2009).

Quando um bebê entra em cena, na relação familiar, a mulher é responsável por dar suporte ao filho, mantendo-o saudável; já do homem, espera-se que se envolva com aspectos que proporcionem à dupla proteção e conforto. Contudo, percebe-se atualmente que as mães estão acionando uma maior participação dos companheiros nos cuidados com os filhos e estes ao experimentar o prazer que esta relação íntima proporciona, mostram satisfação e também buscam essa proximidade com o filho (FALCETO, et al 2008; PRATI, KOLLER, 2011). 
Quando o casal decide ter um filho ou quando ocorre uma gravidez inesperada ou, até mesmo, indesejada, a possibilidade de algo dar errado durante a gestação pode causar apreensão. Caso ocorra alguma complicação poderá haver a necessidade da separação precoce dos pais do seu bebê e o momento do parto, tão aguardado, tornar-se uma situação de crise. Esta separação pode ser a causa de diversos conflitos, pois os pais sonham com um bebê saudável ocorrendo, então, um contraste entre a criança sonhada e aquela que eles visualizam (SIMSEN; CROSSETT, 2004).

Além de a família enfrentar a perda do bebê idealizado, depara-se com a necessidade de obedecer a normas e rotinas hospitalares e, quase sempre, vivencia medos e dúvidas acerca do prognóstico, assim como resistência em aceitar que o filho precise ficar sob cuidados especializados. Esse contexto pode levar ao afastamento ao invés da proximidade desejada e requerida. Em contraposição, se a família for sensibilizada quando incluída no ambiente hospitalar, poderá propiciar ao bebê sentimentos fraternos e de inclusão familiar. Isso terá repercussões não apenas para o pleno exercício da parentalidade como, também, abre-se à participação da família extensa (ROSA, et al 2010).

Dessen e Lewis (1998) apresentam o papel do pai mediante três perspectivas distintas. Para os autores, o pai tradicional era caracterizado como alguém frio e distante, voltado para o mundo do trabalho, a autoridade do lar. O pai moderno é aquele preocupado com o desenvolvimento dos filhos, seja na construção de uma identidade de gênero, da moral, do desempenho escolar, entre outros. E o pai emergente é aquele que participa dos cuidados dos filhos, dividindo as tarefas igualmente, favorecendo o desenvolvimento da criança. Dentro dessa última perspectiva, não há um modelo pronto para a construção dos papéis parentais, ou seja, da parentalidade.

Os pais veem-se com a responsabilidade, além de prover financeiramente a família, também de aproximar-se afetivamente dos filhos, tendo como atribuição os cuidados com sua formação moral e com aspectos educacionais. Este pai percebe essa aproximação como uma forma de crescimento pessoal e este novo modelo marca um novo homem, e consequentemente, um novo pai. O homem contemporâneo deixa de lado o papel de pai conservador, a relação torna-se mais flexível e lhe permite compartilhar com a mulher os afazeres domésticos, além de cuidar e zelar do desenvolvimento dos filhos, atividades essas que desenvolve com prazer. Dentro deste contexto, o homem desfaz a antiga ideia de pai autoritário e passa a mostrar a imagem de pai participativo, ele divide as preocupações e alegrias da gravidez e acompanha ativamente o nascimento e desenvolvimento do filho (MONTGOMERY, 1993). 
Percebe-se que com os avanços sociais, a mulher está assumindo um papel mais atuante na sociedade que demarca sua identidade mais ativa e independente, o que ocasiona a reestruturação de papeis dentro do contexto familiar. Por consequência novas demandas frente à parentalidade, exigindo uma reorganização familiar diferenciada para dar enfoque as necessidades dos filhos (CARVALHO; BRITO, 2008).

Algumas décadas atrás os cuidados com a saúde da criança eram quase exclusivos da mãe. Hoje, o pai tem participado com frequência desses cuidados, junto com a mulher. A "nova paternidade" está além do suporte econômico, incluindo principalmente uma maior participação na alimentação e em todos os aspectos do cuidado do bebê e acompanhamento ao longo do seu desenvolvimento (SILVA, 2010).

Com base na filosofia do cuidado centrado na família, o suporte à mesma e participação dos pais nos cuidados diretos à criança, assim como a inclusão deles nas decisões sobre seu filho, deve ser uma das prioridades nas hospitalizações. A internação prolongada dos bebês e a privação do ambiente aumentam o estresse dos pais e da família, podendo prejudicar o estabelecimento do vínculo e apego (SCOCHI, et al 2003).

\section{3 - Método:}

Para responder aos objetivos da pesquisa, utilizou-se a metodologia de cunho qualitativo. Este tipo de pesquisa investiga significados, motivos, crenças, valores, ou seja, o indivíduo é entendido como parte da realidade social (MINAYO, 2008). Trata-se de uma pesquisa de caráter exploratório, que busca se aproximar dos fenômenos e fatos para desenvolver, esclarecer e modificar as ideias estudadas e construir hipóteses (GIL, 2007).

Foi selecionada uma amostra por conveniência, respeitando os seguintes critérios: crianças com idades até doze meses, em processo de investigação diagnóstica de doença crônica, com até seis meses de internação pediátrica, em um hospital terciário e acompanhadas das mães.

A partir de um estudo piloto, se entrevistou uma mãe, que acompanhava a hospitalização do seu filho. Isso possibilitou a validação da entrevista a ser utilizada na pesquisa quanto à detecção de interferências, correção de problemas referente à aplicação e avaliação da qualidade das questões para o estudo, podendo ajustá-las para que respondessem ao problema de pesquisa, antes do início da mesma.

A coleta de dados se deu com sete mães que contemplavam os critérios de seleção da amostra e destas, seis entrevistas foram consideradas para o estudo. Quanto à delimitação do número de entrevistados, o critério de representatividade da amostragem na pesquisa 
qualitativa não é numérico como na pesquisa quantitativa. A quantidade de pessoas entrevistadas deve, no entanto, permitir que haja a reincidência de informações ou saturação dos dados, isto é, quando nenhuma informação nova é acrescentada com a continuidade do processo de coleta (MINAYO, 2008).

Para a coleta de informações foi utilizada uma entrevista estruturada, semidirigida, com um roteiro, previamente elaborado, de aspecto qualitativo, contando com questões abertas a respeito da percepção da participação paterna na hospitalização do filho. A duração das entrevistas foi de aproximadamente uma hora e foram realizadas nos meses de março a junho de 2016; as respostas foram gravadas digitalmente em áudio, com o consentimento das participantes, e posteriormente transcritas na íntegra para serem analisadas, garantindo assim a fidedignidade das informações. Após a transcrição, o material foi apagado. O contato inicial foi feito pessoalmente, sendo o objetivo da pesquisa explicado de forma breve. Após a concordância do participante, foi marcada a entrevista onde foi firmado o Termo de Consentimento Livre e Esclarecido (TCLE).

As medidas de confidencialidade foram atendidas para a garantia do sigilo no que se refere à identidade das entrevistadas e daqueles que foram citados. Para garantir o anonimato dos sujeitos participantes e facilitar a leitura e interpretação dos resultados, as entrevistadas foram identificadas por Casos e seguidas de números conforme a ordem de realização das entrevistas.

O projeto recebeu Certificado de Apresentação para Apreciação Ética (CAAE) de n ${ }^{\circ}$ 52080115.2.0000.5327 e aprovado conforme parecer $\mathrm{n}^{\circ} 1.458 .848$ através da Plataforma Brasil, pelo CEP da instituição vinculada ao estudo, que atendeu às normas nacionais e internacionais de ética em pesquisa envolvendo seres humanos.

O exame do material resultante das entrevistas foi realizado pelo método de Análise de Conteúdo (BARDIN, 2004). A análise de conteúdo é um método que permite examinar com rigor científico o material das entrevistas, transformando-o de bruto em categorias temáticas para que possam ser tratadas cientificamente, uma vez que tal análise é um conjunto de instrumentos metodológicos que se aplicam a discursos (BARDIN, 2004), oriundos das entrevistas.

A escolha deste método deve-se pelo fato de tratar-se de uma das abordagens mais reconhecidas para analisar material oriundo de métodos qualitativos (MINAYO, 2008). Esse tipo de análise de conteúdo se desenvolve em três fases: a pré-análise, que consiste na exploração do material e o tratamento dos resultados, objetivando a organização do material 
através de ações não estruturadas, abertas, por oposição à exploração sistemática dos documentos (BARDIN, 2004).

Durante a análise procurou-se destacar as particularidades e semelhanças entre os casos, sendo criadas categorias temáticas que foram sendo discutidas com base na literatura sobre o tema. Dois avaliadores cegos fizeram parte da construção das categorias temáticas.

\section{4 - Discussão de Resultados:}

As participantes da pesquisa, todas do sexo feminino, são caracterizadas abaixo:

QUADRO 1 - Características da apresentação das participantes

\begin{tabular}{|c|c|c|c|c|c|c|}
\hline Caso & 1 & 2 & 3 & 4 & 5 & 6 \\
\hline \multicolumn{7}{|l|}{ Mãe } \\
\hline Idade & 23 anos & 21 anos & 38 anos & 25 anos & 25 anos & 21 anos \\
\hline \multirow[t]{2}{*}{ Escolaridade } & Médio & Médio & Médio & Médio & Médio & Médio \\
\hline & Completo & Completo & Completo & Completo & Incompleto & Completo \\
\hline$N \circ$ de filhos & 2 & 1 & 3 & 2 & 1 & 1 \\
\hline \multicolumn{7}{|l|}{ Pai } \\
\hline Idade & 22 anos & 24 anos & 38 anos & 30 anos & 25 anos & 23 anos \\
\hline \multirow[t]{2}{*}{ Escolaridade } & Médio & Médio & Fundamental & Médio & Médio & Superior \\
\hline & Completo & Incompleto & Incompleto & Completo & Completo & Incompleto \\
\hline$N \circ$ de filhos & 1 & 1 & 2 & 2 & 1 & 1 \\
\hline \multicolumn{7}{|l|}{ Casal } \\
\hline $\begin{array}{l}\text { Estão juntos no } \\
\text { momento }\end{array}$ & Sim & Sim & Sim & Sim & Sim & Sim \\
\hline $\begin{array}{l}\text { Tempo de } \\
\text { relacionamento }\end{array}$ & 2 anos & 5 anos & 14 anos & 11 anos & 4 anos & 6 anos \\
\hline \multicolumn{7}{|l|}{ Bebê } \\
\hline Idade & 3 meses & 4 meses & 8 meses & 9 meses & 11 meses & 10 meses \\
\hline $\begin{array}{l}\text { Tempo de } \\
\text { internação }\end{array}$ & 38 dias & 32 dias & 32 dias & 120 dias & 43 dias & 55 dias \\
\hline $\begin{array}{l}\text { Provável } \\
\text { diagnóstico }\end{array}$ & $\begin{array}{l}\text { Sindrome } \\
\text { Genética }\end{array}$ & $\begin{array}{l}\text { Sindrome } \\
\text { Genética }\end{array}$ & $\begin{array}{l}\text { Neuro- } \\
\text { muscular }\end{array}$ & $\begin{array}{l}\text { Gastro- } \\
\text { intestinais }\end{array}$ & $\begin{array}{l}\text { Sindrome } \\
\text { Genética }\end{array}$ & $\begin{array}{l}\text { Grastro- } \\
\text { intestinais }\end{array}$ \\
\hline
\end{tabular}

Fonte: Dados da pesquisa

Diante das informações apresentadas no quadro acima, detectamos que a idade das participantes (Mães) e dos pais, regula entre 21 e 38 anos, apontando para a prevalência de casais jovens. Além disso, há o predomínio de todos os casais estarem juntos, pelo menos, há dois anos. Ressaltamos também os prováveis diagnósticos dos bebês, lembrando que no 
momento da entrevista, ainda estavam em processo de investigação de diagnóstico, relacionados a Síndromes Genéticas, problemas Neuromuscular e Gastrointestinal.

A partir da leitura e interpretação das falas obtidas, surgiram cinco categorias, conforme os critérios de similaridade e coerência com os assuntos discorridos e os objetivos propostos. A seguir, serão apresentadas e discutidas as seguintes categorias: 1)“Ambivalência materna: Trabalho X Cuidado do filho"; 2)“Satisfação materna com a participação do pai no cuidado com o filho hospitalizado"; 3)"Principal rede de apoio à mãe"; 4)“Temor da perda X Sensibilidade paterna" e 5)"Vínculo pai/filho na internação pediátrica", conforme Quadro 2 a seguir:

QUADRO 2- Questões de Pesquisa e Categorias Temáticas

QUESTÕES DE PESQUISA

CATEGORIAS TEMÁTICAS

\begin{tabular}{cc}
\hline Como a mãe se organiza para & Ambivalência, retorno para o trabalho e cuidado com o \\
acompanhar a internação o filho & filho
\end{tabular}

A mãe está satisfeita com a

participação do pai na Participativo, presente, apoio e acolhimento à mãe hospitalização

Em que a mãe percebe que o pai poderia participar mais

Suficiente dentro do espaço que ela oferece a ele

Com o a mãe vê que é para o pai, Desejo de unir a família em função da separação pela ser pai de um filho hospitalizado rotina hospitalar, Sentimento de insegurança, medo e perda

Como percebe a relação pai-filho Relação em construção, proximidade, vínculo pai-bebê, durante a hospitalização revive a falta paterna, fortalece a saúde do filho

Fonte: Dados da pesquisa

\section{1 - Ambivalência materna: Trabalho X Cuidado do filho:}

$\mathrm{O}$ estudo evidenciou as incertezas maternas diante dos empregos e as necessidades que os filhos hospitalizados exigem, mostrando que existem dúvidas para as mães de qual caminho seguir. Elas refletem sobre suas carreiras profissionais e estabilidade financeira, ao mesmo tempo em que visualizam as demandas exigidas pelos filhos com possibilidade 
diagnóstica de doenças crônicas, que precisam de uma rotina de cuidados diferenciados. Segundo Schimitz (2012); Bezerra, Fraga (1996), o advento de uma enfermidade e, como consequência a hospitalização, desestrutura a família, pois há uma mudança de papéis entre os seus membros. A mulher se vê dividida entre as atividades de esposa, trabalhadora e mãe, que tem a "obrigação", segundo a sociedade e ela mesma, de cuidar do filho doente. Essa questão fica evidente nas seguintes falas:

\begin{abstract}
Ainda estou pensando, e não cheguei numa conclusão, não consegui mesmo, porque minha vontade é não deixar de trabalhar e minha outra vontade, é de não deixar o meu filho. Tô em dúvida do que fazer, porque eu tenho uma estabilidade nesse emprego, já tô lá há bastante tempo, eu gosto muito de trabalhar, gosto do que eu faço, não trabalho por obrigação, tenho prazer no que eu faço. Em contrapartida, penso no meu filho (Mãe 1).
\end{abstract}

Eu tava de licença maternidade, que termina dia 9 de maio, daí eu tenho que voltar a trabalhar, ela tá internada aqui e precisa do meu acompanhamento... não sei como vai ser daqui pra frente, já trabalho há 2 anos nesse lugar (Mãe 2).

Percebemos que estas mães, envolvidas e recompensadas em suas atividades laborais, o que reflete no tempo de serviço em seus locais de atuação profissional e no prazer pelo o que exercem. Ao se tornarem mães de filhos hospitalizados, suas atribuições podem se tornarem maiores, o que faz com que não consigam dar conta da rotina da hospitalização e da rotina do trabalho. A respeito da inclusão de mulheres no mercado de trabalho, Bertolini (2002), expõe que a mulher busca tanto a realização pessoal quanto profissional, desejando independência econômica enquanto preserva seu papel de mãe. A construção de uma identidade profissional é fonte de status, poder e autoestima, contribuindo para uma melhor saúde mental da mulher. Isso pode favorecer relacionamentos interpessoais mais positivos na esfera familiar, inclusive com os filhos (BERTOLINI, 2002; GRAVENA, 2006; D'AFFONSECA, 2005).

Diante da dúvida em trabalhar ou cuidar do filho, duas participantes deste estudo, frente à investigação diagnóstica para doença crônica, optaram por abrir mão do trabalho, que lhe garantia segurança econômica e prazer, para dar lugar àquilo que para elas era mais importante e lhes exigia maior atenção no momento: cuidar de seus filhos, como se confirma a seguir:

Eu era concursada pública, daí eu pedi exoneração do cargo pra poder cuidar dele (...). Em alguns momentos eu sinto falta do trabalho (...) então a minha rotina é voltada pra cuidar dele e o meu marido cuida do trabalho mesmo, da onde vem a nossa renda" (Mãe 3).

Depois que o meu filho nasceu fiquei no período de licença do trabalho, e depois vimos que eu não tinha como voltar a trabalhar, ele continuou hospitalizado e eu precisava cuidar dele (...) no início, foi estranho e difícil, agora eu tô acostumada (Mãe 5). 
(...) o meu marido queria que eu não voltasse a trabalhar e só ficasse em casa com o bebê, eu tinha muita vontade de continuar trabalhando. Diante de todo esse processo, nós reorganizamos a nossa vida, para dar conta dos cuidados dele, eu não voltei para o trabalho e fico aqui toda a semana, conto com a ajuda da minha família e do meu esposo, mas eu que fico mais tempo no hospital (Mãe 6).

A intensidade do envolvimento da mulher com a carreira e a importância atribuída a esta para sua identidade pessoal são fatores que podem provocar problemas de saúde física e mental. Pode haver dificuldade para lidar com as condições e demandas de trabalho, bem como as atividades laborais em concorrência com as demandas de cuidados dos filhos, principalmente durante a infância e adolescência destes (DINIZ, 1999). Os problemas aparecem quando as responsabilidades em cada esfera (trabalho e família) se sobrepõem, como por exemplo, um filho doente necessitando de cuidados em um dia de trabalho. Quando ocorrem conflitos entre as demandas profissionais e familiares, é preciso optar entre estas duas responsabilidades altamente importantes, o que leva a custos na vida profissional ou familiar, ou em ambas (GOTTLIEB; KELLOWAY; BARHAM, 1998).

O fato das mulheres deixarem de trabalhar para cuidar do filho, pode ser entendida como uma vivência de luto. Por causar uma reação emocional desconfortável e diferente, este luto materno revelaria a perda do lugar que elas faziam parte e se reconheciam enquanto trabalhadoras, exercendo as suas atividades profissionais. Conforme Rowling (1995), o luto é entendido como uma constelação de reações psíquicas, conscientes e inconscientes, diante de uma perda significativa. É uma experiência complexa que transcende o âmbito individual, uma experiência moldada pelo passado, presente e esperanças no futuro, expressos na linguagem e comportamento, sendo uma crise que atinge o indivíduo, sua família e os sistemas mais amplos da sociedade dos quais participa.

No estudo, percebemos que essas decisões das mães deixarem os seus empregos foram tomadas em conjunto pelo casal e a renda familiar ficou a cargo do esposo, que tinha o comprometimento com as despesas econômicas da família. Essa decisão não interferiu na participação do pai no cuidado com o filho durante a hospitalização, porém as mães tinham consciência desse acordo entre o casal e estavam disponíveis em tempo integral para o filho, enquanto o pai era mais presentes nos momentos de folga do trabalho. Para Benetti (2001) a sociedade tem modificado a sua mentalidade a respeito da participação do pai nas tarefas de cuidados e criação dos filhos, e da influência do pai no sistema familiar e no desenvolvimento infantil. Isso se deu devido às mudanças socioeconômicas que ocasionaram a entrada das mulheres no mercado de trabalho, acarretando uma maior participação masculina na vida 
doméstica, um interesse em discutir e questionar a estrutura familiar e o papel paterno e materno.

Sendo assim, ao entrevistar as mães, observamos que o período de hospitalização da criança constitui um momento ímpar em suas histórias de vida, pelos sentimentos e emoções que permeiam seu ser. A doença de seu filho gera mudanças nas rotinas dessas mães e nas relações familiares, pelos diversos papéis desempenhados pela mulher, tais como: esposa, mãe e trabalhadora.

\section{2 - Satisfação materna com a participação do pai no cuidado com o filho hospitalizado:}

A visão do pai como alguém que desempenha unicamente o papel de provedor na vida da família e dos filhos vem sendo substituída pela percepção de que ele é um membro que pode exercer inúmeros papéis significativos, dentre os quais o de companheiro, protetor, cuidador, modelo a ser seguido, orientador e professor (LAMB, 1997). A paternidade tem recebido destaque na literatura nas últimas décadas, especialmente o que tange às mudanças na família contemporânea, nas funções e nos papéis de homens e mulheres na sociedade (SOUZA; BENETTI, 2009).

Por outro lado, mesmo com a emergência deste e ampliação do modelo de pai, Lewis e Dessen (1999) ressaltam que qualquer análise da paternidade precisa começar com a observação de que em poucas sociedades o pai assume os cuidados rotineiros com relação às crianças. Os homens continuam se representando e sendo representados por papéis fora do centro das interações familiares, o que pode ser justificado pelas pressões do trabalho, pela falta relativa de recompensa por seu engajamento nos cuidados das crianças e pelas sutis negociações entre os parceiros sobre a parte a ser desempenhada pelo homem na família (LEWIS; DESSEN, 1999).

De acordo com os autores acima, talvez por esses motivos o pai seja notado pela sua ausência, principalmente em relação à vida de crianças pequenas, o que fortalece um estereótipo negativo sobre seu papel dentro da família. Nesse sentido, no que concerne às pesquisas sobre paternidade foi o desenvolvimento do construto de envolvimento paterno, proposto pelos autores Lamb, Pleck, Charnov e Levine (1985), que chamou atenção para uma dimensão do comportamento dos pais até então negligenciada em estudos anteriores (PLECK, 1997). Embora a definição inicial deste construto estivesse relacionada à quantidade de tempo que os pais despendem com seus filhos, sem preocupação com o conteúdo do envolvimento, foi este mesmo autor quem advertiu sobre a necessidade de se repensar o conceito para que 
fossem incluídas as dimensões qualitativas do comportamento paterno. Surgiu, assim, o conceito de envolvimento paterno positivo que inclui, além do nível quantitativo do envolvimento paterno, também a preocupação com o conteúdo e a qualidade desse envolvimento (PLECK, 1997).

No caso de pais de filhos hospitalizados, as mães remeteram a uma participação paterna positiva, atrelando ao pai, um papel de dedicação e responsabilidade constantes frente às demandas vividas no hospital, fazendo com que ele consiga, muitas vezes, ter uma dupla jornada, alternando horário de trabalho com horários no hospital. Notamos que este novo modelo de pai, como descrita na literatura, é reconhecido também pelas mães em relação aos pais de seus filhos em investigação diagnóstica de doença crônica e estão representadas nas seguintes falas:

\footnotetext{
Ele participa tanto quanto eu. Se tem $100 \%$ é metade minha e metade dele; é uma dedicação nossa, porque ele sempre quer tá aqui, ele tem a mesma responsabilidade que eu (Mãe 1).
}

\begin{abstract}
Ah, ele tá junto comigo desde que ela nasceu, todas as vezes que ela internou, ele trabalhava daí ele saia do serviço e ia para o hospital, dormia no hospital com a gente e no outro dia ele ia direto trabalhar (Mãe 2).
\end{abstract}

Ele cuida e é presente, como se estivesse em casa, claro que tem a questão do trabalho, que faz ele tá mais presente nos finais de semana, em alguns dias da semana ele saí do trabalho e vem ver como nosso filho tá (Mãe 5).

O envolvimento paterno, conforme os autores clássicos e que iniciaram os estudos nessa abordagem, Lamb, Pleck, Charnov e Levine (1985), pode ser visto a partir de três componentes: interação, acessibilidade e responsabilidade. A interação é como o contato direto do pai com a criança, através de cuidados e atividades compartilhadas; já acessibilidade refere-se à presença e à disponibilidade do pai para a criança, acontecendo ou não a interação direta entre eles. A responsabilidade, refere-se ao papel que o pai exerce nos cuidados com a criança. Para estes autores, dentre os possíveis fatores que influenciariam o envolvimento paterno, pode-se ressaltar: a motivação, que seria o desejo de envolvimento deste pai, podendo estar relacionado, entre outros fatores, à quantidade de envolvimento que seus próprios pais tiveram para com ele; as habilidades, que são necessárias para o sucesso e prazer nos cuidados da criança; o apoio, que é a aprovação do envolvimento paterno por outras pessoas, tais como a esposa, a mãe e os colegas de trabalho; e os fatores institucionais, como o emprego deste pai que poderia impedir um maior envolvimento com a criança (LAMB,1997; PARKE, 1996; PICCININI, et al, 2004).

As mães deste estudo expressaram satisfação com a participação positiva do pai na hospitalização do filho. Com este modelo de pai contemporâneo, representado pelo seu papel 
presente, ativo e preocupado com as demandas da família, elas atribuíram qualidades à figura paterna e expressaram sentimento de gratidão marcado por esta presença. Conforme Porta e Terzis (2010) cada um destes homens, constituindo um novo modelo, busca, então, exercer funções de um pai que julga ideal. O pai atual tem a tendência a abandonar o papel exclusivo de provedor e assumir funções compartilhadas e complementares com a companheira-mãe, o que é relatado nos seguintes recortes:

(...) eu vejo que é bem raro os pais estarem presentes aqui no hospital, então agradeço por ele ser assim, preocupado com o filho e disposto a me ajudar no que for preciso (Mãe 5).

Ele sempre foi super presente, desde o nascimento do nosso filho, ou até antes mesmo, na minha gestação e quando a gente fez os planos que queríamos ter mais filhos (Mãe 4).

Constatou-se no estudo que algumas mães tinham dificuldades para dar mais espaço ao pai, restringindo a participação e as tarefas desempenhadas por eles. Elas sentiam-se mais preparada para o cuidado com filho doente e que o fazer do pai era suficiente dentro do que elas limitavam e permitiam, o que poderia ser mais desenvolvido e expandido. Dessa forma, se reescreveria o estigma das mães, conforme os autores Bezerra e Fraga (1996), que no âmbito hospitalar, a mulher introjeta a ideia que o cuidado com o filho doente compete somente a ela e, por isso, empenha-se em suprir todas as necessidades da criança, assumindo ela mesma a condição de provedora destes cuidados.

\section{(...) só se eu desse mais espaço pra ele (risos), deixar ele mais tempo aqui no hospital com o nosso filho, eu sendo a visitante e ele o acompanhante, entende?! (Mãe 1).}

Não tem um momento que eu possa te dizer que eu acho que ele tem que participar mais, ele é totalmente presente, ele faz as mesmas coisas que eu, ele muda (...) ele só não deu banho ainda, porque eu não deixei (risos), porque eu sempre fiz isso né (Mãe 2).

Ele sempre foi participativo, ele até queria tá mais presente aqui, mas não tem como (Mãe 3).

Dessa forma, a representação social do papel de pai sofreu muitas mudanças no decorrer dos tempos e tem evoluindo em seus conceitos. Antes, o pai exercia o poder da casa, sua autoridade valia para os filhos e para mulher, sendo ele o membro provedor. No entanto, dada à presença das mulheres no mercado de trabalho, tem se modificado essa antiga estrutura, determinando novos arranjos familiares. Sob a perspectiva psicanalítica a figura paterna se encontra em reconstrução, sendo que o pai expõe sua face afetiva, estando mais presente, de modo oposto à concepção tradicional que se caracteriza pelo distanciamento físico e afetivo (MARTINEZ; FONSECA; SCOCHI, 2007). 


\section{3 - Principal rede de apoio à mãe:}

A doença, sobretudo a doença grave, provoca na família uma desorganização funcional, e quando os seus membros não podem assumir o papel habitual, as relações interpessoais estão perturbadas, manifestando-se reações emocionais e de ansiedade, comprometendo o cotidiano. Para enfrentar esta situação, os membros da família, desenvolvem estratégias muito variadas, entre elas, a procura de informação acerca da doença, a obtenção de suporte junto de familiares e amigos ou a busca de conforto na religião. Pinto, Montinho e Gonçalves (2008), no seu estudo sobre o impacto da doença na família, referem que o tempo atua como um elemento interventor na reorganização da família, funcionando como moratória necessária à integração das mudanças que a família sofre. Estes autores verificaram no seu estudo que a reação da família pode ser negativa quando a ela muda a sua dinâmica relacional e não aceita as mudanças ocorridas, o que pode tornar-se patológico e paradoxal em termos comunicacionais.

No que se referiu ao contexto familiar, expresso pelas múltiplas mudanças ocorridas em função da hospitalização do filho e os sentimentos decorrentes disso, estão destacadas nas falas das participantes, o desejo dos pais em ter a sua família organizada fora do contexto hospitalar, sendo que este pai, é o encarregado pelos outros filhos que estão em casa e o cuidador responsável pela família extensa.

(...) o meu esposo tá em casa, nossa família não tem mais aquela rotina de família, e ele diz isso, que ele quer a família dele junto de novo, esse cansaço de estarmos separados, de cada um estar em um lugar (Mãe 1).

(...) mas como tem a outra menina de 11 anos que ele cuida, ela tem a rotina de criança, de escola, daí a gente combinou, ele cuida das coisas lá em casa (...) (Mãe 2).

“Quando não tá no trabalho, tá em casa com a mana, porque ela também precisa dele, ele sempre foi um bom pai pra ela e agora mais ainda, porque aguenta as pontas em casa (Mãe 4).

No período da hospitalização do filho processam-se muitas mudanças na dinâmica familiar, principalmente no tocante às atividades antes desenvolvidas pela mulher. Por ocasião da hospitalização, os membros da família devem reorganizar-se para dar continuidade à atenção requerida pelos filhos que ficaram em casa (BEZERRA; FRAGA, 1996).

A fragilidade das participantes desta pesquisa foi um ponto a ser destacado, devido ao longo tempo no hospital, às intercorrências, agravos e incertezas em relação à saúde da criança. Elas expressaram que estes momentos foram amenizados com as demonstrações de afeto e apoio do companheiro, que além de participativo no que se remetia ao filho 
hospitalizado, também era uma figura de suporte e amparo para elas, mães, sendo esse companheiro uma figura estruturante no funcionamento psíquico das companheiras:

A participação do meu esposo é muito importante pra mim como mãe, como dona de casa. Eu aprendi tudo de família com ele e com os filhos, ele é um paizão (Mãe 1).

(...) meu esposo sempre do meu lado nessa correria toda (Caso 2).

Pela ajuda, companheirismo, pelo apoio. Sempre fizemos nossos planos juntos (...) (Mãe 4).

(...) não deixa faltar nada pra gente (Mãe 5).

(...) como companheiro, ele sempre me apoia e participa do crescimento do nosso filho (Mãe 6).

A importância da presença, em especial do marido, é para as mães de bebês hospitalizados sinônimo de apoio, inclusive para o bebê. Embora a presença da mãe junto ao filho nas unidades hospitalares seja bastante valorizada, é necessário lembrar que a mulher necessita de uma rede de apoio e, ao valorizar e incentivar a presença do pai do bebê se proporciona tal ajuda (SCHMIDT, et al, 2012).

A doença e a hospitalização da criança podem ser vistas como fatores de estresse, que para além de afetar o desenvolvimento normal da criança, também atinge as relações sociais dentro do sistema familiar. Estudo desenvolvido por Marinheiro (2002) revela que a doença pode interferir no estado psicológico dos pais, sendo que as consequências ou impacto de uma doença/hospitalização sobre o funcionamento familiar podem ocorrer em qualquer uma destas áreas: financeira, social, somática, comportamental, vida mental consciente e inconsciente.

Portanto, percebemos que os pais tiveram papel fundamental, pois assumiram a função de apoiar e cuidar de suas companheiras, possibilitando-as que se dedicassem integralmente às necessidades dos filhos hospitalizados. Winnicott (1988) assinala que é papel do pai apoiar a mãe neste estado de preocupação materna primária, período no qual ela se encontra vulnerável e com maior sensibilidade. Tal postura denota a sensibilidade paterna, que permitiu aos pais sintonizar-se com seus filhos e suas esposas, percebendo as reais necessidades neste período e a dependência absoluta do bebê aos seus pais.

\section{4 - Temor da perda $X$ Sensibilidade paterna:}

As mães expuseram em suas falas a sensibilidade paterna, o modo como o pai sente e vivencia a hospitalização do filho, transmitindo as dificuldades, os sofrimentos e as sobrecargas emocionais. Notou-se que quando os pais estão à espera de um diagnóstico os 
sentimentos acionados são mais intensos e podem ser negados ou não verbalizados por eles, sendo expressos através do choro, que é identificado pelas mães.

Eu vejo ele um pouco sobrecarregado emocionalmente com a hospitalização, eu vejo que ele tá cansado na limitação dele (Mãe 1).

Olha, pra ele, eu acho que é bem difícil (...) eu já peguei ele chorando no banheiro. eu sei que ele sente muito por ela estar no hospital e por não ter resposta do que ela pode ter (Mãe 2).

O pai nem pode ficar muito tempo aqui, senão ele fica chorando (risos), ele sofre muito de ver nosso filho assim, ele se sensibiliza, fica nervoso e emotivo. O pai é mais fraquinho pra lidar com as coisas do hospital, fraquinho no sentido de ficar triste, abatido (Mãe 3).

Acho que é difícil até hoje para ele ser pai de um bebê hospitalizado, saber da fragilidade do nosso filho, ele ainda tem muito medo do que pode acontecer (Mãe 4).

(...) então eu vejo vários momentos de descontrole dele, por não suportar ver o filho dele sofrendo (Mãe 6).

Percebemos que pelo fato dos pais estarem menos tempo no hospital, devido a outras atribuições já mencionadas neste estudo (familiares e de trabalho), as mães os perceberam mais inseguros, diante do manejo hospitalar com o filho, visto que estas crianças exigem um suporte diferenciado por utilizarem mecanismos tecnológicos cada vez mais modernos e que garantam a vida. Essa insegurança paterna, pode de alguma forma ser gerada pelo fazer materno diário: como ela realiza a rotina de cuidados corriqueiramente, ela acaba não oportunizando que o pai faça, e quando permite, de alguma forma, transmiti o desconforto da insegurança a ele, contendo o seu fazer. As participantes da pesquisa mostraram isso no decorrer de suas falas, ficando implícito o quanto se acham mais preparadas, seguras e capazes para exercer tais cuidados com o filho, em função da maternagem exercida na relação mãe/bebê:

Eles se entendem muito bem, eu digo que eles não se entendem tanto quanto eu e o nosso filho, mas eles se entendem bem, porque assim (...) tem vezes que ele tá posando aqui e o bebê tem crises de choro, que ele quer a mãe; eu acho que mãe e filho é uma coisa e pai e filho é outra (Mãe 1)

Ele morre de medo de dar banho, porque ele é assim, todo molinho, tem que ter muito cuidado, meu marido tem receio de machucar, de fazer alguma coisa errada, daí as vezes eu ajudo ele a pegar, pra tentar dar mais segurança pra ele (Mãe 3).

Eu percebo que ele tem alguns receios nos cuidados, talvez por não praticar sempre como eu, acaba se sentindo mais inseguro, com medo de errar, eu até incentivo, mas percebo que ele treme, tem medo de fazer algo errado, não que ele queira (Mãe 6)

Além da sensibilidade e insegurança paterna diante da criança hospitalizada, as participantes deste estudo, sentiram o medo, transmitido pelo pai, de perdê-lo. Esse medo 
remete a impotência de ver/ter o filho doente, hospitalizado e esperando um diagnóstico de uma doença que tem a alta probabilidade de se fazer presente para o resto da vida, sem expectativas do que ele, enquanto pai pode fazer para aliviar a dor da criança. Neste instante elas resgataram o histórico da família desde a gestação, nascimento e espera do diagnóstico, mostrando que os pais vivenciam este processo com o temor e desconforto da perda:

\begin{abstract}
Logo que o nosso filho nasceu ele ficou muito, muito desesperado, não só por ele ter nascido antes, mas a gente quase morreu no nascimento dele, foi bem complicado pra ele, ver tudo aquilo e dar contar. De alguma forma ele pensou que a gente podia morrer (...) e muitas vezes depois também, as pioras que o bebê teve, foram lutas constantes pela vida dele, nas idas e vindas da UTI (...) (Mãe 4).
\end{abstract}

Eu percebo muito essa sensibilidade dele e até o medo de perder o nosso filho em alguns momentos, demonstrando que é sofrido sim ter um filho que precisa de muitos cuidados e que tá no hospital, ninguém tá no hospital porque quer né, e saúde é uma coisa séria (Mãe 6).

Conforme o estudo desenvolvido por Jorge (2004), os pais sentem a hospitalização do seu filho como uma separação da criança, uma quebra na organização do cotidiano (distanciamento, despesas, faltas ao trabalho) e é acompanhada por sentimentos que vão desde medo de perder o filho a impotência e culpa. Dupas, et al (2012) acrescentam que a possibilidade de descoberta de um diagnóstico de doença crônica para os pais provoca muito sofrimento, medo e angústia. A ameaça que a doença representa para a vida da criança remete a uma reflexão sobre sua conduta como pai, pois ao ver o filho sofrer, o pai acaba vivenciando um sofrimento que considera ser maior que a do seu próprio filho, pois se sente impotente e fraco.

Depois que o pai enfrenta o desafio da hospitalização da criança, depara-se com a responsabilidade e a vontade de ver e estar com ela. Em geral, este homem sente a perda do filho ideal e o primeiro sentimento é quase sempre de decepção. Seu filho é ainda mais frágil e vulnerável do que havia imaginado, é despreparado para a vida extrauterina e, agora, sem a proteção do corpo materno. Para o pai, as imagens registradas de seu bebê, às vezes extremamente pequeno, dependente de aparelhos, medicações e de cuidados especializados, trazem consigo inseguranças, temores e frustrações (KLAUS; KENNEL, 1993).

\title{
4.5 - Vínculo pai/filho na Internação Pediátrica:
}

As mães, participante deste estudo, foram unânimes em relatar que não visualizam empecilhos na vinculação pais/filhos em função de estarem hospitalizados. Elas discorreram associando, em alguns momentos, a construção do laço parental com a adaptação e 
fortalecimento ao estado de saúde da criança, referindo a interferência dessa aprendizagem para ambos, pais e filhos, como produtiva e não limitada pela possibilidade de doença crônica.

\footnotetext{
“... eu acho que se o nosso filho não fosse doente, ele seria o mesmo pai pra ele, sem diferenças, o vínculo de pai e filho seria exatamente igual” (Mãe 1).

"Aqui quando ele chega e o nenê escuta a voz dele, tem que ver, fica faceiro de ver o pai. $O$ vínculo deles é bom, ele é um ótimo pai para nosso filho e o nenê percebe quando o pai tá pertinho" (Mãe 3).
}

"Ele adora e percebe quando o pai dele tá aqui, pela voz, pelo toque, pelo carinho de pai que transmite mesmo. $O$ vínculo de pai e filho, fortalece de alguma forma a saúde do nosso bebê"” (Mãe 4).

"O vínculo deles é muito bom, acho que junto com o meu marido ser pai, veio toda essa adaptação a saúde do nosso filho e ao hospital, o fato dele tá aqui no hospital não impede a relação deles" (Mãe 5).

"É uma relação boa, um vínculo bom, tem que ver a felicidade do bebê quando o pai chega, bagunça é com ele, e meu marido também é super carinhoso e dedicado quando tá aqui, incentiva o desenvolvimento do nosso filho, que pra mim é bem importante, também não coloca limitações por causa da doença" (Mãe 6).

Neste sentido, as participantes, conseguiram expandir o seu entendimento sobre o vínculo pai/filho, salientando a ligação afetiva, motivada pelo carinho e afago entre a dupla. Para elas o pai disponibilizava através do toque, voz e presença um desenvolvimento afetuoso, confortável e saudável emocionalmente para a criança.

$\mathrm{Na}$ experiência de adoecimento do filho, o pai reconstrói seu papel em um processo de maior interação e afetividade com ele, redireciona sua vida superando preconceitos, como o de que o homem não pode chorar ou demonstrar seus sentimentos, e que sua única responsabilidade é prover o sustento da família, valorizando a sua presença na vida do filho (DUNAS, et al 2012).

Pontuamos como importante, através das percepções das participantes, a relação pai/filho baseada em suas primeiras relações familiares, como uma experiência que organiza os pais perante seus compromissos/responsabilidades com os filhos e conota um sentido de como exercer a sua paternidade guiando-se no que teve de seus pais. Além disso, surgiu também, em algumas falas, a reparação pelo o que pai que não teve, neste momento o pai revive a falta e cria um vínculo diferente do que teve com o seu pai. Esse vínculo seria uma experiência nova para esse pai, permitindo uma relação pai/filho com sentimentos despertados do que ele sentiu diante da falta, do que não teve.

Ele nunca viu o pai dele, nasceu sem pai, na certidão de nascimento dele, é só o nome da mãe, então pra ele é importante estar próximo da filha dele, porque ele se sente bem, ele tá sendo o que ele nunca teve né?! (Mãe 2). 
Eu percebo que isso vem da família dele, ele é o filho mais velho, o pai abandonou eles. Não sei se é porque ele conviveu pouco com o pai e sente essa falta e quer fazer diferente, não quer ser para os filhos o que ele não teve, alguma coisa assim, essa relação deve ter (Mãe 4).

(...) e também eu vejo muito o reflexo das nossas famílias sabe?! (Mãe 6).

Os pais reconhecem o que é transmitido transgeracionalmente e, graças a isso, poderão seguir caminhos diferentes em sua vida, modificar comportamentos até então esperados e, a partir de reflexões sobre sua própria história familiar, construir sua individualidade enquanto pais (FALCKE; WAGNER, 2005). É importante perceber que o homem consegue reinventar seu papel e construir a subjetividade de pai, transformando-se a partir de valores novos e antigos (GOMES; RESENDE, 2004).

Com esta categoria, percebeu-se através do olhar da mãe, os sentimentos paternos acionados pela hospitalização e espera de um diagnóstico de doença crônica do filho. Os pais temeram pela possibilidade da perda que acompanha o adoecimento e a cronicidade da saúde da criança. Isso os deixa sensibilizados e fragilizados e pode repercutir na insegurança dos cuidados.

\section{Considerações finais:}

Este estudo permitiu refletir a participação do pai na hospitalização do filho em investigação diagnóstica de doença crônica, sob o olhar materno. As mães relataram como são as experiências das famílias neste momento considerado de crise, e a nova reorganização familiar, com a atuação dos pais de seus filhos neste cenário.

Sabemos, conforme a literatura, que os estudos atuais têm focado nas mães como principais cuidadoras, porém, com esta pesquisa, destaca-se a importância da ampliação do espaço e do olhar para a figura paterna, uma vez que ele também é fonte essencial no cuidado do filho hospitalizado e, além disso, é uma figura de amparo às mães. Dessa maneira as equipes de saúde, podem trabalhar e atuar neste sentido, de maior inserção paterna, potencializando o fazer do pai no cenário hospitalar. Assim, possibilitar uma forma de melhor assistir a essas famílias, integrando a visão para o casal com o filho doente ao invés da compreensão individualizada mãe/filho. Enfatizamos que tanto os pais, como as mães precisam de vias de escuta e acolhimento, de forma a minimizar as consequências emocionais para a família das vivências hospitalares.

Podemos identificar algumas mudanças no conceito de paternidade, a partir das entrevistas, que nos remete a um pai mais preocupado e dedicado à sua família, não apenas no 
aspecto financeiro, que predominou historicamente, mas também simbolizando um novo papel a ser desempenhado no exercício da paternidade no contexto hospitalar. Este cenário visto como um lugar onde a participação paterna promove o fortalecimento familiar e contribui para amparar a situação de crise vivenciada pela família, a investigação diagnóstica de doença crônica. Podemos assim salientar que o modelo atual de pai se reconstrói a todo o momento, em diferentes âmbitos e aspectos, contribuindo para o funcionamento e demanda que cada família enfrenta.

Os progressos tecnológicos nos centros terciários de assistência em saúde permitem o aumento significativo nas situações de sobrevida, diante de doenças complexas. Isso reflete naturalmente nos investimentos das famílias na saúde de seus filhos e a estruturação destas neste novo contexto. Dessa forma as equipes de saúde podem estar cada vez mais alinhadas para atuar com os novos arranjos familiares e a propiciar a participação de todos os envolvidos na perspectiva de saúde e desenvolvimento do paciente, assim possibilitando cuidados também com os envolvidos, em forma de escutas, olhares e acolhimentos, principalmente o pai, que é uma figura que está firmando o seu papel também neste cenário.

Mesmo sendo um estudo onde se abordou a participação do pai, as participantes mostraram necessidade de serem escutadas e de falar dos seus sentimentos enquanto mães, das suas formas de cuidado e manejo com a criança, enfatizando em alguns momentos que o espaço é limitado por elas próprias para atuação paterna no hospital, não conseguindo se distanciar dos companheiros quando o assunto é a saúde do filho. Portanto, os achados também demonstraram o desejo, a necessidade e a satisfação das mães diante de um espaço para falarem de seus sentimentos e contarem sobre a sua intensa experiência. Cabe ressaltar a importância de serem implementados programas multidisciplinares de acompanhamento para o casal. Este suporte emocional poderia contribuir de forma preventiva para os problemas de desorganização emocional materno/paterno, auxiliando-os também a refletirem e discutirem sobre a presença do pai na hospitalização do filho e o quanto elas conseguem acionar, estimular e facilitar esta participação.

É importante salientar que segundo os relatos das mães, que os pais vivem esse momento de maneira bastante intensa, considerando as limitações impostas pela hospitalização e espera de diagnóstico de doença crônica. É possível reconhecer que os sentimentos, tarefas, preocupações e expectativas são executados com empenho conforme a capacidade psíquica de cada um, para dar suporte à companheira e contribuir para os cuidados com o filho, atendendo as necessidades e fazendo esta uma experiência fundamental para a sobrevivência física/emocional da criança. 
Para finalizar, a realização desta pesquisa infere à relevância deste contexto para o campo da Psicologia enquanto ciência e profissão e também contata-se a necessidade de serem realizados mais trabalhos neste contexto. A participação paterna para a criança hospitalizada é necessária para o desenvolvimento de todos os seus aspectos físicos, emocionais e cognitivos, e também é um suporte necessário para as mães, mulheres e companheiras. É importante levar-se em consideração que o profissional da psicologia pode contribuir para o desempenho de um trabalho em equipe, pensando em saúde: saúde da criança hospitalizada, saúde da família, saúde no ambiente hospitalar, saúde em Unidades Pediátricas. Dessa maneira a psicologia pode atuar junto às equipes de saúde, como também pode proporcionar um espaço ativo as famílias de crianças hospitalizadas, promovendo saúde de modos distintos e tendo um olhar ampliado a todos os envolvidos.

\title{
MATERIAL PERCEPTION OF PARENT PARTICIPATION IN THE HOSPITALIZATION OF THE CHILD IN DIAGNOSTIC INVESTIGATION OF CHRONIC DISEASE
}

\begin{abstract}
:
The study aimed to identify the participation of the father in the hospitalization of the child during the diagnostic investigation, based on reports of maternal perception. Six mothers, whose children were hospitalized in a diagnostic investigation of chronic disease, were enrolled in a tertiary hospital located in the south of the country. The qualitative methodology was used with an exploratory character, in which a structured interview with the participants was performed. The analysis of content indicated that the presence of the father in the hospitalization generates benefits both for the sick child and for the mother/wife who feels welcome, functioning as the main network support and support for the psychic organization of the woman. It was highlighted the intense paternal suffering experienced at the moment, the insecurity to perform some health care with the child and the fear of losing it. Mothers perceive parents involved with their children and able to develop a positive parent/child bond in Pediatric Unit.
\end{abstract}

Keywords: Parenting; Infant hospitalization; parent/child bonding.

\section{Referências:}

BARDIN, L. Análise de conteúdo. 3. ed. Lisboa: Edições 70, 2004.

BENETTI, S. O papel paterno na família japonesa- uma questão de presença física ou psicológica? Revista Psico, v.32, n.1, p.97-113, 2001. 
BERTOLINI, L. B. A. Relações entre o trabalho da mulher e a dinâmica familiar. São Paulo: Vetor, 2002.

BEZERRA, L. F. R.; FRAGA, M. N. O. Acompanhar um filho hospitalizado: compreendendo a vivência da mãe. Revista Brasileira de Enfermagem, v. 49, n. 4, p. 611-624, out./dez, 1996.

CARVALHO, J. B. L.; BRITO, R. S. Atitudes do pai diante do nascimento. Revista Rene, v.9, n.4, pp.82-90, 2008.

CASTRO, E.; THOMAS, C. Parentalidade no contexto da doença crônica infantil. In C. A. \& Piccinini, P. Alvarenga (Eds.). Maternidade e Paternidade: A parentalidade em diferentes contextos (pp.253- 268). São Paulo, Brasil: Casa do Psicólogo, 2010.

D'AFFONSECA, S. M. Importância do envolvimento materno para o autoconceito e desempenho acadêmico das crianças de baixo nível socioeconômico. Dissertação de mestrado apresentado ao Programa de Educação Especial, Universidade Federal de São Carlos, SP, 2005.

DAMASIO, A.; RUMEN, F. Mães na assistência à criança com câncer, o enfrentamento sem a figura paterna em casa de apoio. In N.A.G. Nucci \& E. Perina. (Orgs). As dimensões do cuidar em psiconcologia pediátrica: desafios e descobertas (pp.183-199) Campinas, SP: Livro pleno, 2005.

DINIZ, G. Homens e mulheres frente à interação casamento trabalho: aspectos da realidade brasileira. In T. F. Carneiro (Org.), Casal e família: entre a tradição e a transformação (pp. 31-54). Rio de Janeiro: Nau, 1999.

DUPAS, G. et al. Câncer na infância: conhecendo a experiência do pai. Revista Mineira de Enfermagem, v.16, n.3, p.348-354, 2012.

EIZIRIK, C. L. (org.). O ciclo da vida humana: uma perspectiva psicodinâmica. Porto Alegre: Artmed Editora, 2001.

FALCETO, O. G. et al . Fatores associados ao envolvimento do pai nos cuidados do lactente. Rev. Saúde Pública, São Paulo, v.42, n.6, dez. 2008. Disponível em: $<$ http://www.scielo.br/scielo.php?script=sci_arttext\&pid=S003489102008000600009\&ng=pt \&nrm=iso> Acesso em: 15 out. 2016.

FALCKE, D.; WAGNER, A. A dinâmica familiar e o fenômeno da transgeracionalidade: definição de conceitos. In: WAGNER, A. (Coord.). Como se perpetua a FAMíliA? A transmissão dos modelos familiares. Porto Alegre: Editora PUC-RS, p.25-46, 2005.

FLECK, A. C.; FALCKE, D.; HACKNER, I. T. Crescendo menino ou menina: a transmissão dos papéis de gênero na família. Em Wagner, A. (Org.). Como se perpetua a família?: a transmissão dos modelos familiares (pp.107-121). Porto Alegre: EDIPUCRS, 2005.

FREITAS, W. M. F. et al. Paternidade: Responsabilidade social do homem no papel de provedor. Revista de Saúde Pública, v.43, n.1, pp.85-90, 2009.

GIL, A. C. Métodos e técnicas de pesquisa social. 5. ed. São Paulo: Atlas, 2007. 
GOMES, A. J. S.; RESENDE, V. R. O Pai Presente: O Desvelar da Paternidade em Uma Família Contemporânea. Psicologia: Teoria e Pesquisa, Brasília, v.20, n.2, p.119-125, 2004.

GÓNGORA, J. El impacto psicosocial de la enfermedad crónica em la família. In J. A. Ríos (Ed.). La família: Realidad y mito. (pp. 176-201). Madrid: Centro de Estudios Ramón Areces, 1998.

GOTTMAN, J.; DECLAIRE, J. Inteligência emocional e a arte de educar nossos filhos: como aplicar os conceitos revolucionários de inteligência emocional para uma compreensão da relação entre pais e filhos. (A. C. da Silva Trad.). Rio de Janeiro: Objetiva, 2001.

GOTTLIEB, B. H.; KELLOWAY, E. K., BARHAM, E. Flexible work arrangements managing the work-family boundary. Chichester: John Wiley, 1998.

GRAVENA, A. C. Retorno ao trabalho após o nascimento de um filho: percepções de professoras sobre sua experiência. Dissertação de Mestrado. Universidade Federal de São Carlos: São Carlos, 2006.

HOUZELL, D. As implicações da parentalidade. In: Solis-Ponton, L. (Ed.). Ser pai, ser mãe. Parentalidade: um desafio para o terceiro milênio. São Paulo, Brasil: Casa do Psicólogo, 2004.

JORGE, A. M. Família e hospitalização da criança: (re) pensar o cuidar em enfermagem. Loures: Lusociência, 2004.

KLAUS, M. H.; KENNEL, J. H. Pais/bebês: a formação do apego. Porto Alegre: Artes Médicas; 1993.

LAMB, M. E. Fathers and Child Development: An Introductory Overview and Guide. Em M. E. Lamb (Ed.), The role of the father in child development (pp. 1-18). New York: John Wiley \& Sons, 1997.

LAMB, M. E. et al. Paternal behavior in humans. New York: American Zoologist, 1985.

LEWIS, C.; DESSEN, M. A. O Pai no Contexto Familiar. Psicologia: Teoria e Pesquisa, v. 15, n.1, p.9-16, 1999.

MARINHEIRO, P. Enfermagem de ligação: cuidados pediátricos no domicílio. Coimbra: Quarteto Editora, 2002.

MARTINEZ, J. G.; FONSECA, L. M. M.; SCOCHI, C. G. S. Participação das mães/pais no cuidado ao filho prematuro em unidade neonatal: significados atribuídos pela equipe de saúde. Revista Latinoamericana de Enfermagem, v.15, n.2, p.239-46, 2007.

MINAYO, M. C. S. Pesquisa Social: teoria, método e criatividade. 27 ed. Petrópolis, RJ: Vozes, 2008.

MONTGOMERY, M. O novo pai. $12^{\mathrm{a}}$ ed. São Paulo: Prestígio; 2005.

MUSCARI, M. E. Coping with cronic illness. AJN, v. 98, p. 20-2, 1998. 
OLIVEIRA, E.; SOMMERMAN, R. A família hospitalizada. In Romano B. W (Ed.). Manual de Psicologia Clínica para Hospitais (pp. 117-37). São Paulo, Brasil: Casa do Psicólogo, 2008.

PICCININI, C. A.; GOMES, A. G.; MOREIRA, L. E.; LOPES, R. S. Expectativas e sentimentos da gestante em relação ao seu bebê. Psicologia: Teoria e pesquisa, v.3, n.20, p.223-232, 2004.

PINTO, J. M.; MONTINHO, L. M. S.; GONÇALVES, P. R. C. O doente queimado e a dinâmica familiar: o impacto da doença na família. Referência, v. 2, n 6, p. 69-76, 2008.

PLECK, J. H. Paternal Involvement: Levels, Sources and Consequences. Em M. E. Lamb (Ed.), The role of the father in child development (pp. 66-103). New York: John Wiley \& Sons, 1997.

PORTA, L.K.; TERZIS, A. Vínculos e internação de filho em UTI neopediátrica. Psicologia [internet], v.41, n.4, p.488-94, 2010. Disponível em: < http://revistaseletronicas.pucrs.br/ojs/index.php/revistapsico/article/viewFile/5324/5957> Acesso em: 20 out. 2016.

PRATI, L. E.; KOLLER, S. H. Relacionamento conjugal e transição para a coparentalidade: perspectiva da psicologia positiva. Psicologia Clínica, v.2, n.1, p.103-118, 2011.

ROWLING, L. The disenfranchised grief of teachers. Omega, 1995.

RIBEIRO, N. A família enfrentando a doença grave da criança. In: Elsen I, Marcon S. S.; Silva M. R. S. O viver em família e sua interface com a saúde e a doença. (pp. 183-198) Maringá (PR), Brasil: UEM, 2004.

ROWLING, L. The disenfranchised grief of teachers. Omega, n.31, 317-329, 1995.

ROSA, R. et al. Mãe e filho: os primeiros laços de aproximação. Escola Anna Nery Revista de Enfermagem, v.1, n.14, p.105-12, 2010.

SCHIMITZ, E. M. R. et al. A problemática da hospitalização infantil: aspectos psicológicos. Enfermagem em Pediatria e Puericultura. Rio de Janeiro: Atheneu, p. 181-195, 1989.

SILVA, M. C. P.; SOLIS-PONTON, L. Ser pai, ser mãe - parentalidade: um desafio para o terceiro milênio. São Paulo, Brasil: Casa do Psicólogo, 2004.

SILVA, J.M. O lugar do pai: uma construção imaginária. São Paulo: Annablume, 2010.

SIMSEN, C. D.; CROSSETTI, M. G. O. O significado do cuidado em UTI neonatal na visão de cuidadores em enfermagem. Revista Gaúcha de Enfermagem, Porto Alegre/RS, v. 2, n. 25, p.231-42, agosto 2004.

SPITZ, R. O primeiro ano de vida. São Paulo: Martins Fontes, 1998. 
SCHMIDT, K. T. et al. A primeira visita ao filho internado na unidade de terapia intensiva neonatal: percepção dos pais. Escola Anna Nery Revista de Enfermagem, v.16, n.1, p.73$81,2012$.

SCOCHI, C.G.S. et al. Incentivando o vínculo mãe-filho em situação de prematuridade: as intervenções de Enfermagem no Hospital das Clínicas de Ribeirão Preto. Revista Latino América de Enfermagem, v.4, n.11, p.539-43, jul/ago 2003.

STAUDT, A. C. P.; WAGNER, A. Paternidade em tempos de mudança. Psicologia teoria e prática, São Paulo, v.10, n.1, p.174-185, jun. 2008. Disponível em $<$ http://pepsic.bvsalud.org/scielo.php?script=sci_arttext\&pid=S151636872008000100\&lng=pt $\& n r m=$ iso $>$. Acesso em: 20 out. 2016.

SOUZA, C. L. C.; BENETTI, S. P. C. Paternidade contemporânea: Levantamento da produção acadêmica no período de 2000 a 2007. Paideia, Ribeirão Preto, v.19, n.42, p.97106, 2009.

WINNICOTT, D. W. Preocupação materna primária. In D. W. Winnicott (Ed.). Textos selecionados: da pediatria à psicanálise (pp. 491-498). São Paulo: Imago, 1988.

ZORNING, S. Transmissão psíquica: uma vida de mão dupla? In: Feres Carneiro (Ed.). Casal e família: permanências e rupturas (pp. 25- 41). São Paulo, Brasil: Casa do Psicólogo, 2009.

Data de recebimento: 14/02/2017.

Data de aceite: 01/11/2017.

\section{Sobre as autoras:}

Taline Cheron é Residente da Residência Multiprofissional Integrada Em Saúde - Ênfase Saúde da Criança- do Hospital de Clínicas de Porto Alegre- RS. Endereço Eletrônico: talinemail@gmail.com

Cláudia Simone Silveira dos Santos é Psicóloga e Doutora em Ciências da Saúde: Ginecologia e Obstetrícia. Endereço Eletrônico: csssantos@hcpa.edu.br 